\title{
Sorting of the Structure of Corrugated Yarn Production in Cluster Enterprises
}

\author{
Ismailov Nurulla Tuychiboevich \\ Namangan Institute of Engineering and Technology, Namangan City, The Republic of Uzbekistan \\ Email:innnt027@mail.ru,innnt027@gmail.com
}

How to cite this paper: Tuychiboevich, I.N. (2021) Sorting of the Structure of Corrugated Yarn Production in Cluster Enterprises. Engineering, 13, 184-196. https://doi.org/10.4236/eng.2021.134014

Received: August 3, 2020

Accepted: April 22, 2021

Published: April 25, 2021

Copyright $\odot 2021$ by author(s) and Scientific Research Publishing Inc. This work is licensed under the Creative Commons Attribution International License (CC BY 4.0).

http://creativecommons.org/licenses/by/4.0/

\begin{abstract}
In the article, the methods of processing and obtaining multicomponent raw materials were investigated with the properties of multicomponent threads obtained from fiber waste cluster enterprises in textile production, the interrelation of the components sorting composition. To solve the problem, we used the cause-effect relationship of information theory from the grid planning Matrix, solving the dependence of raw materials, physical and mechanical parameters and the established characteristics of the product. Empirical correlations were obtained on the nature and mechanism of the relationship between factors, which allowed the system to establish a theory of control and prediction of behavior. The methods of evaluation used in this study make it possible to expand the information base with respect to these indicators and to use them in the production of fabrics and threads with established characteristics.
\end{abstract}

\section{Keywords}

Raw Material, Waste, Cotton, Viscose, Polyester, Sorting, Optimization, Multi-Component Thread, Linear Density, Stretching, Matrix Grid Planning Method

\section{Introduction}

Currently, improving the quality of textile products, in particular, yarn from the same raw materials, depending on market demand is an urgent task, which contributes to increasing the export capacity of products. The production of high-quality, globally competitive products based on the use of new, more advanced technology is the most important task of the textile industry. The quality of textiles depends to a large extent on the uniformity, purity and strength of the yarn. Improving the quality indicators of textile products can be achieved by in- 
troducing and using modern equipment that operates on more advanced technological principles [1] [2] [3].

The efficiency of spinning production largely depends on the rational use of raw materials, which to a greater extent affects the cost of the final product-yarn. It is known that as a result of processing of textile fiber, fibrous waste is released, which is divided into spun and non-spun. Among them, spun waste is of great value, since it allows you to save a full-fledged fiber and reduce the cost of production [2] [4] [5].

Therefore, the study of the possibility of waste-free processing of fibers into yarn is an urgent problem, in connection with which the goal of complete processing of spun waste into yarn is set.

\section{Material and Methods}

The types of yarns made up of several components are very diverse. The properties and scope of yarns determine their structure and the fibrous composition of the mixture. Reinforced yarn, in contrast to ordinary or mixed yarns, obtained on spinning machines and consisting entirely of fibrous materials evenly distributed throughout the entire volume, is usually made in two steps, first a core is made, and then an outer layer called a braid is applied to it. Any natural and chemical fibers, a wide range of complex yarns, as well as all possible fibrous waste from the textile industry can be used as components of the reinforced yarn [1]-[7].

It is characteristic that the resulting breaking load of the reinforced yarn is the sum of the breaking loads of the rod and the braid, which depend on the strength characteristics of the fibers.

In order to determine the quality of the mixture, the properties of the individual components that make up the structure of the yarn were studied.

\subsection{Analysis of the Physical and Mechanical Properties of Fibrous Waste}

To expand the range of yarns, the geometric properties of fibrous waste were studied.

In the studies, it was assumed to use fibrous waste of the spinning group, released in production conditions.

As it is known, this enterprise used cotton, viscose and polyester fibers. Therefore, the main attention was paid to these fibers and, accordingly, their spinning waste was studied—nut and scattering fluff ST N 3, carded brush (ST N II) and combed wool ST N 17.

Structural and compositional fibrous waste was studied in a production laboratory using a standard method.

The tests were carried out in three agility. After checking the homogeneity of the variance of the average indicators, they were summarized in Table 1.

The indicators relate to waste generated during the processing of type II grade 
I cotton fiber sort.

By analyzing this table, one can be convinced that the length of the fibers is quite spinnable. Carded fleece has a maximum average length $(35.2 \mathrm{~mm})$. The breaking load of the fibers in the carded belt also has a maximum value (27.8). As for the viscose fibers, on the contrary, the carded fleece has a shorter fiber length $(35.4 \mathrm{~mm}$ versus $36.2 \mathrm{~mm}$ ) than in the nut. The breaking load of the fibers in the carded thread is less by $1.2 \mathrm{~mm}$ in comparison with the flap nut.

Also, the corresponding indicators of polyester fiber were determined, which differ in their strength, amounting to $46.3 \mathrm{sn} /$ tex in the nut and 47.8 in the carded thread.

Thus, the fiber of three types is at the same length in length, and in terms of linear density, the range of the value is 0.02 tex, therefore, they may well be mixed.

Taking into account the production conditions, the mixing of the components was carried out at the first transfer of the draw frames.

For this, for each component, the corresponding mixtures were compiled for the production of a tape. The proportion of components is given in Table 2.

Table 1. Basic properties of fibrous waste.

\begin{tabular}{|c|c|c|c|c|c|c|}
\hline \multirow[b]{2}{*}{ No. } & \multirow{2}{*}{$\begin{array}{l}\text { Name of the } \\
\text { waste }\end{array}$} & \multirow{2}{*}{$\begin{array}{c}\text { Linear } \\
\text { Density, } \\
\text { T, tex }\end{array}$} & \multirow{2}{*}{$\begin{array}{l}\text { Average } \\
\text { length, } \\
\mathrm{L}, \mathrm{mm}\end{array}$} & \multicolumn{2}{|c|}{ Breaking load } & \multirow{2}{*}{$\begin{array}{c}\text { The content } \\
\text { of vices and } \\
\text { weeds, \% }\end{array}$} \\
\hline & & & & $\begin{array}{l}\text { absolute } \\
\text { R.sn }\end{array}$ & $\begin{array}{l}\text { relative, } \\
\text { R.sn/tex }\end{array}$ & \\
\hline & \multicolumn{6}{|c|}{ cotton fiber } \\
\hline 1 & Nut and fluff scabby & 0.143 & 34.3 & 3.4 & 25.48 & 32.3 \\
\hline 2 & Carded scrub & 0.143 & 35.2 & 3.6 & 27.6 & 12.6 \\
\hline 3 & Comb fleece & 0.143 & 34.7 & 3.1 & 26.2 & 1.9 \\
\hline \multicolumn{7}{|c|}{ viscose wool } \\
\hline 4 & Fluff scutching & 0.152 & 36.2 & 20.4 & 15.7 & 1.3 \\
\hline 5 & Carded scrub & 0.152 & 35.4 & 19.2 & 14.1 & 0.9 \\
\hline \multicolumn{7}{|c|}{ polyester fiber } \\
\hline & Fluff scabby & 0.163 & 35.3 & 46.3 & 26.8 & 1.1 \\
\hline & Carded scrub & 0.163 & 36.3 & 47.3 & 20.7 & 0.6 \\
\hline
\end{tabular}

Table 2. The composition of the mixture components.

\begin{tabular}{ccccc}
\hline & & \multicolumn{3}{c}{ Types of Disposals } \\
\cline { 3 - 5 } No. & Name of the waste & $\begin{array}{c}\text { Nut and fluff } \\
\text { scuffed, in } \%\end{array}$ & $\begin{array}{c}\text { Carded scrub, } \\
\text { in \% }\end{array}$ & $\begin{array}{c}\text { Combed hair, } \\
\text { in \% }\end{array}$ \\
\hline 1 & Cotton waste & 25 & 35 & 45 \\
2 & Viscose waste & 10 & 90 & - \\
3 & Polyester waste & 10 & 90 & - \\
\hline
\end{tabular}


Based on the distribution of waste, a three-component mixture was achieved, taking this into account, an experiment with sequential simplex planning was chosen to study the relationship of the composition of the property, which is carried out in order to achieve an almost stationary region of the response function, which is also well formalized and easy to optimize.

\subsection{Rationalization of the Sorting Composition of Single and Reinforced Yarns}

Experimental studies were carried out in a production laboratory on a PR-150-1 machine, where the further production of single and reinforced yarns makes it possible to provide the same conditions for spinning and reinforcement.

Table 3, the matrix of the lattice method of planning the experiment for the case of three components is presented and the following designations are adopted:

$X_{1}$-coded value of the share of cotton waste in the mixture, \%;

$X_{2}$-coded value of the proportion of viscose waste in the mixture, \%;

$X_{3}$-coded value of the proportion of waste polyester fibers in the mixture, $\%$;

$Y_{1}$-relative breaking load, sn/tex;

$Y_{2}$-square uneven that at breaking load, \%;

$Y_{3}$-quadratic unevenness in linear density, \%;

$Y_{4}$-elongation at break, \%.

Based on the data in Table 3, the coefficients of the polynomials are calculated and the following dependences of the optimization parameters on the composition of the sort are established.

$$
\begin{aligned}
Y_{1}\left(P_{c M}\right)= & 6.12 X_{1}+7.6 X_{2}+7.63 X_{3}+4.18 X_{1} X_{2}+2.42 X_{1} X_{3} \\
& +4.72 X_{2} X_{3}+1.17 X_{1} X_{2} X_{3} \\
Y_{2}\left(H_{p}\right)= & 8.3 X_{1}+11.4 X_{2}+16 X_{3}+1.4 X_{1} X_{2}+14.6 X_{1} X_{3} \\
& +50.4 X_{2} X_{3}+10.88 X_{1} X_{2} X_{3} \\
Y_{3}\left(H_{T}\right)= & 5.7 X_{1}+3.3 X_{2}+4.1 X_{3}+4.4 X_{1} X_{2}+1.6 X_{1} X_{3} \\
& +6 X_{2} X_{3}+33.3 X_{1} X_{2} X_{3} \\
Y_{4}\left(y_{o}\right)= & 5 X_{1}+4.5 X_{2}+4.6 X_{3}+12.6 X_{1} X_{2}+6.4 X_{1} X_{3} \\
& +18.6 X_{2} X_{3}+48.6 X_{1} X_{2} X_{3}
\end{aligned}
$$

Since the simplex of lattice matrices is saturated (the number of experiments is equal to the number of determined coefficients in the polynomial), there are no degrees of freedom to check the adequacy. Therefore, to check the adequacy of the obtained models (I), additional experiments are carried out at some control points of the factor space.

The number of control points and their location on the simplex depend on the problems of the complexity of the experiment and the high cost. Most often, the control points are chosen either in the zone of the factor space that is most interesting for the researcher, or so that, if necessary, they can be used to construct 
a polynomial of a higher degree [1]-[10].

In Table 4, the results of additional experiments are given which were carried out to check the adequacy of the models.

The homogeneity of the dispersion of the experiments was verified by the Cochran criteria.

$$
G_{R}=S^{2} u \max \{Y\} S u^{2}\{Y\}
$$

Calculations have shown that the variances of all optimization parameters are homogeneous, since the condition GR $<$ GT is satisfied.

The reproducibility dispersion was calculated by the following formula

$$
S^{2}\{\bar{y}\}=\frac{1}{N m} R S^{2} u\{y\}
$$

The adequacy of the obtained models was checked at each control point according to the Student's criterion, the calculated value of which was determined by the formula.

$$
t_{R}=\frac{\left(y_{u}-y R_{u}\right) m}{S\{\bar{y}\} 1-j}
$$

Comparing the calculated and tabular values of the Student's criterion, it was found that all models are adequate to the experimental data and can be used for calculations.

Table 3. Planning matrix and experiment results.

\begin{tabular}{cccccccc}
\hline \multirow{2}{*}{$\begin{array}{c}\text { Experience serial } \\
\text { number }\end{array}$} & \multicolumn{3}{c}{ Share of components } & \multicolumn{5}{c}{ Average parameter values } \\
\cline { 2 - 8 } & $X_{1}$ & $X_{2}$ & $X_{3}$ & $Y_{1}$ & $Y_{2}$ & $Y_{3}$ & $Y_{4}$ \\
\hline 1 & 1 & 1 & 0 & 6.12 & 8.3 & 5.7 & 5 \\
2 & 0 & 0 & 0 & 7.6 & 11.4 & 3.3 & 4.5 \\
3 & 0 & 0 & 1 & 7.63 & 16 & 4.1 & 4.6 \\
4 & 0.5 & 0.5 & 0 & 7.9 & 9.5 & 3.4 & 7.93 \\
5 & 0.5 & 0 & 0.5 & 7.44 & 8.5 & 4.5 & 6.43 \\
6 & 0 & 0 & 0.5 & 8.8 & 11.1 & 5.23 & 9.2 \\
7 & 0.333 & 0.333 & 0.333 & 8.1 & 12.3 & 5.6 & 6.5 \\
\hline
\end{tabular}

Table 4. Results of control experiments.

\begin{tabular}{cccccccc}
\hline \multirow{2}{*}{$\begin{array}{c}\text { Experience } \\
\text { number }\end{array}$} & \multicolumn{3}{c}{ Proportion of components } & \multicolumn{5}{c}{ Average parameter values } \\
\cline { 2 - 8 } & $X_{1}$ & $X_{2}$ & $X_{3}$ & $Y_{1}$ & $Y_{2}$ & $Y_{3}$ & $Y_{4}$ \\
\hline 7 & 0.333 & 0.333 & 0.333 & 8.133 & 12.3 & 4.5 & 6.5 \\
8 & 0.15 & 0.70 & 0.15 & 8.38 & 6.02 & 4.4 & 8.7 \\
9 & 0.70 & 0.15 & 0.15 & 7.4 & 5.9 & 3.8 & 7.3 \\
10 & 0.5 & 0.3 & 0.2 & 7.4 & 6.1 & 4.0 & 8.2 \\
\hline
\end{tabular}


Interpolation of the test results is recommended to select the optimal zone for the proportions of components.

For this purpose, curves were constructed that represent diagrams of the composition of properties, on which, within the simplex, a family of isoclines is depicted, showing the nature of the change in the parameters of the mixture of the composition of properties in Figures 1-4.

Analyzing the isoclines, it is easy to make sure that the optimal ratios of the mixture components are within the range of $X_{1}=33.333 ; X_{2}=33.333 ; X_{3}=$ 33.333 .

Thus, on the basis of the experiment carried out, the values of the components that ensure the optimum yarn quality have been determined.

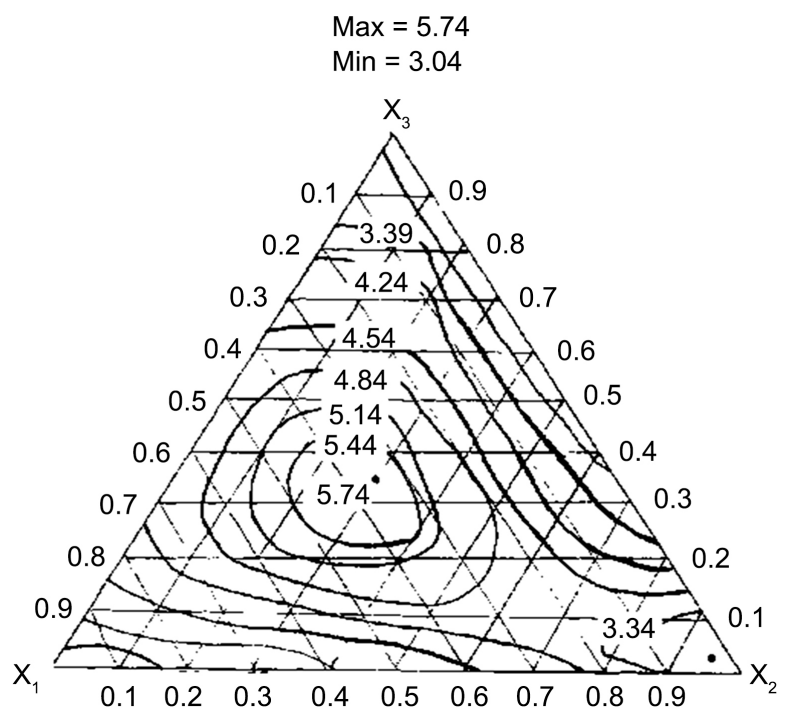

Figure 1. Isolines of the dependence of unevenly and spinning according to the linear density of a single yarn on the sorting composition, $\%$.

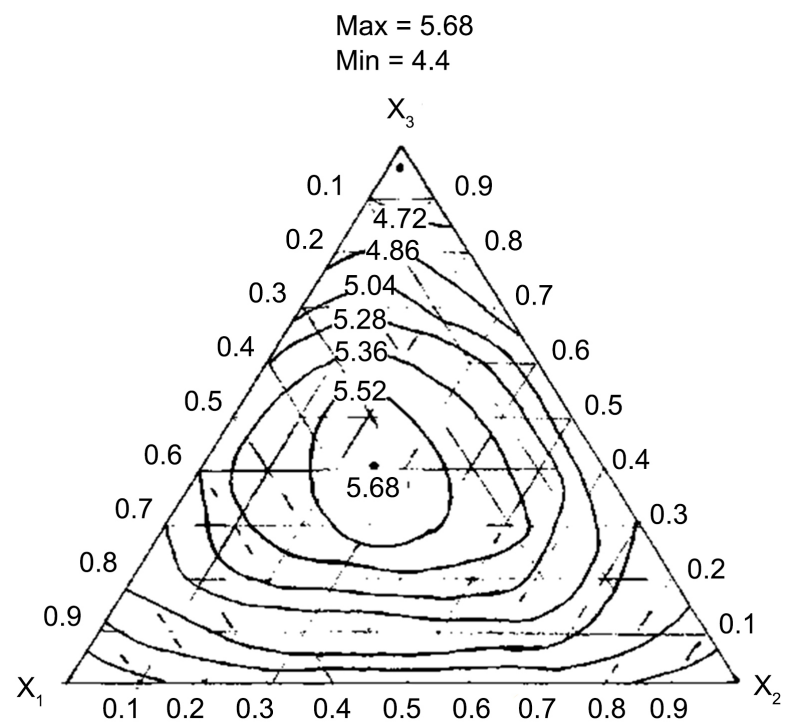

Figure 2. Elongation at break, \%. 


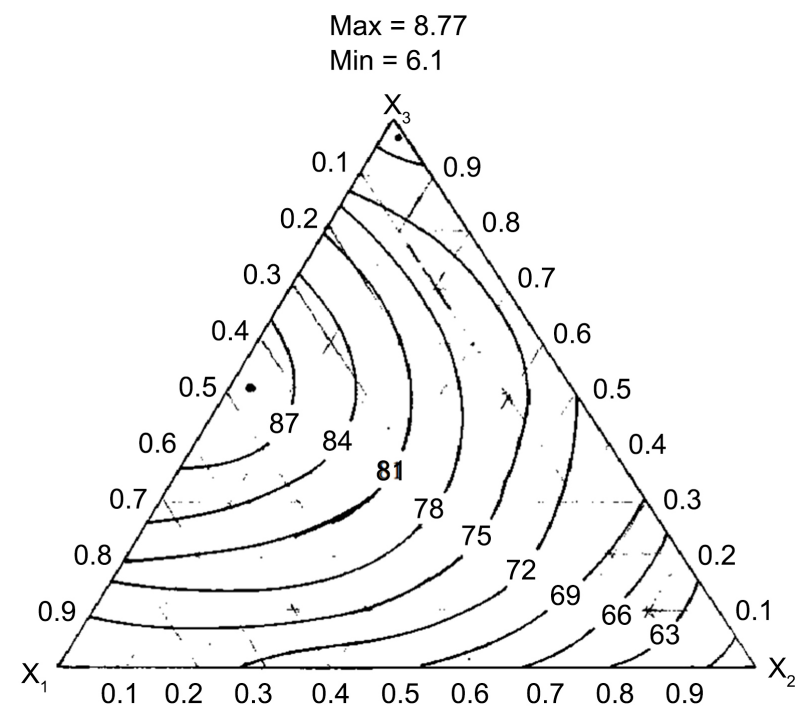

Figure 3. Relative breaking load, sn/tex.

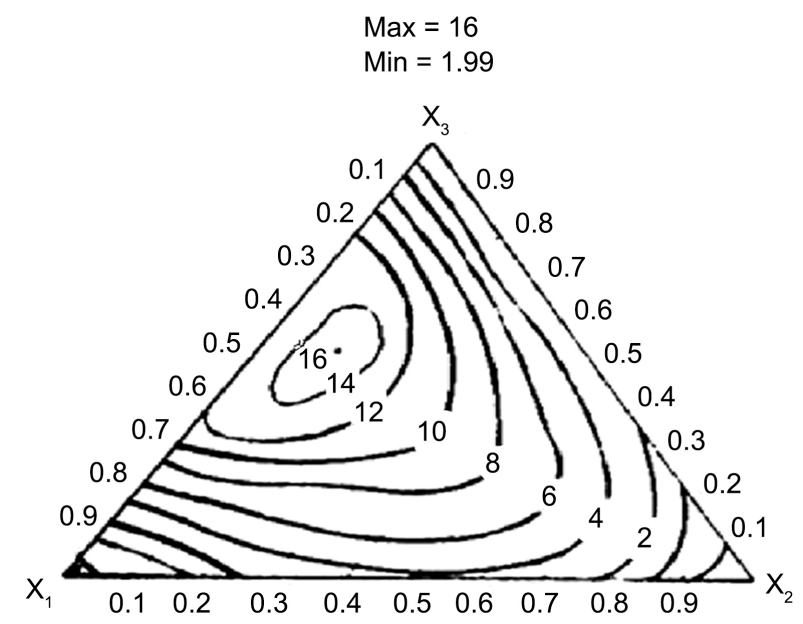

Figure 4. Square uneven breaking load, \%.

Similar experiments to optimize the sorting composition were carried out for yarn production. In this case, the input optimization parameters acquire new values.

It is known that the properties of a reinforced yarn, consisting of a core thread to the outer sheathing layer, depend on the combination of the fibrous composition of the components to their values.

When forming a reinforced yarn on PR-150-1, the sheathing layer completely covers the core thread, forming the outer layer, while the fibers in the braid are compacted to the core by means of torsion, which creates a frictional force that resists breaking forces.

Taking into account that the friction force depends not only on the twist, but also on the properties of the braid fibers, the dependences of the main properties of the reinforced yarn on the sorting composition in the presence of a rod were investigated. 
The planning matrix and research results are shown in Table 5.

Based on the results of the experimental data, the coefficients of the polynomial were calculated, and adequate equations were obtained:

$$
\begin{aligned}
Y_{1}\left(P_{c M}\right)= & 10.2 X_{1}+9.9 X_{2}+10.1 X_{3}+3 X_{1} X_{2}+18 X_{1} X_{3} \\
& +0.4 X_{2} X_{3}+174 X_{1} X_{2} X_{3} \\
Y_{2}\left(H_{p}\right)= & 10.1 X_{1}+11 X_{2}+13.1 X_{3}-4.2 X_{1} X_{2}-24 X_{1} X_{3} \\
& -21.4 X_{2} X_{3}+105.8 X_{1} X_{2} X_{3} \\
Y_{3}\left(H_{T}\right)= & 5.4 X_{1}+5.2 X_{2}+5.2 X_{3}-0.4 X_{1} X_{2}-3.2 X_{1} X_{3} \\
& -2 X_{2} X_{3}+120.9 X_{1} X_{2} X_{3} \\
Y_{4}\left(y_{o}\right)= & 8.3 X_{1}+7.2 X_{2}+7.6 X_{3}-2 X_{1} X_{2}-1.4 X_{1} X_{3} \\
& +0 X_{2} X_{3}+16.2 X_{1} X_{2} X_{3}
\end{aligned}
$$

The adequacy of the regression equation was checked on the basis of complementary experiments (Table 6).

Comparing the response surfaces and analyzing the isolines, one can conclude that the optimal ratios of the components are $X_{1}=33.3 ; X_{2}=33.3 ; X_{3}=33.3$, which corresponds to cotton waste in the amount of $33.3 \%$, waste $33.3 \%$, polyester waste $33.3 \%$.

Property composition diagrams are shown in Figures 5-8.

Table 5. Planning matrix and experiment results.

\begin{tabular}{cccccccc}
\hline & \multicolumn{3}{c}{ Proportion of components } & \multicolumn{5}{c}{ Average parameter values } \\
\cline { 2 - 8 } Variants & $X_{1}$ & $X_{2}$ & $X_{3}$ & $Y_{1}$ & $Y_{2}$ & $Y_{3}$ & $Y_{4}$ \\
\hline 1 & 1 & 0 & 0 & 10.2 & 10.1 & 5.4 & 8.3 \\
2 & 0 & 1 & 0 & 9.9 & 11.0 & 5.2 & 7.2 \\
3 & 0 & 0 & 1 & 10.1 & 13.1 & 5.2 & 7.6 \\
4 & 0.5 & 0.5 & 0 & 9.3 & 9.5 & 5.2 & 7.25 \\
5 & 0.5 & 0 & 0.5 & 9.7 & 4.5 & 2.5 & 7.6 \\
6 & 0 & 0 & 0.5 & 10.1 & 4.7 & 4.7 & 7.4 \\
7 & 0.333 & 0.333 & 0.333 & 10.3 & 7.5 & 4.3 & 7.1 \\
\hline
\end{tabular}

Table 6. The result of control experiments.

\begin{tabular}{cccccccc}
\hline \multirow{2}{*}{ Variants } & \multicolumn{3}{c}{ Proportion of components } & \multicolumn{5}{c}{ Average parameter values } \\
\cline { 2 - 8 } & $X_{1}$ & $X_{2}$ & $X_{3}$ & $Y_{1}$ & $Y_{2}$ & $Y_{3}$ & $Y_{4}$ \\
\hline 7 & 0.333 & 0.333 & 0.333 & 10.08 & 9.65 & 8.9 & 7.85 \\
8 & 0.15 & 0.70 & 0.15 & 12.37 & 8.74 & 6.88 & 7.8 \\
9 & 0.70 & 0.15 & 0.15 & 12.11 & 8.9 & 6.82 & 7.95 \\
10 & 0.50 & 0.3 & 0.2 & 16.3 & 9.85 & 8.8 & 8.56 \\
\hline
\end{tabular}




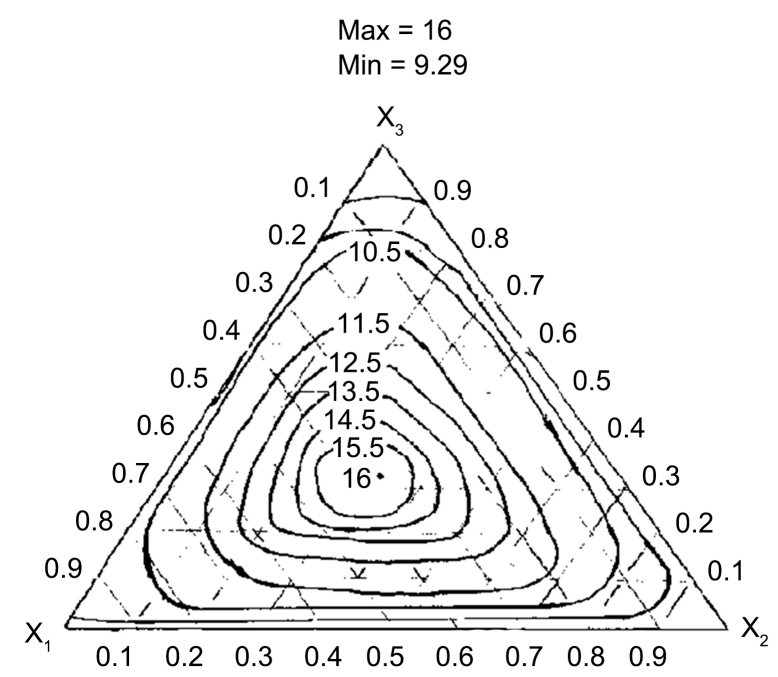

Figure 5. Relative breaking load, sn/tex.

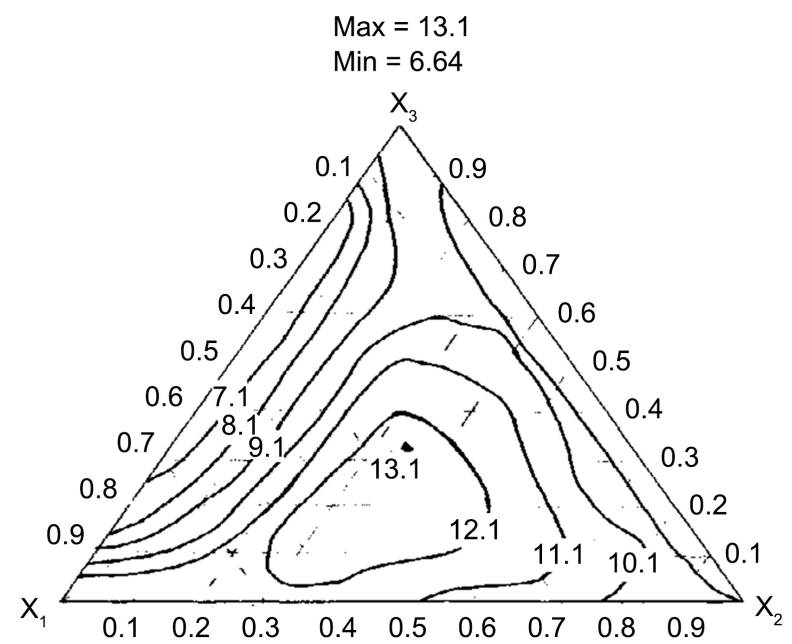

Figure 6. Roughness at breaking load, \%.

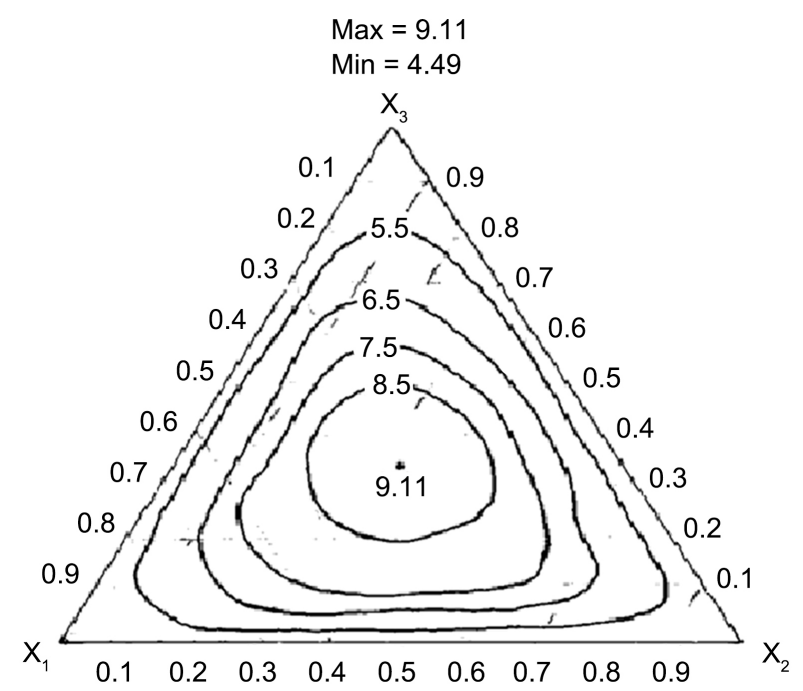

Figure 7. Roughness in linear density, \%. 


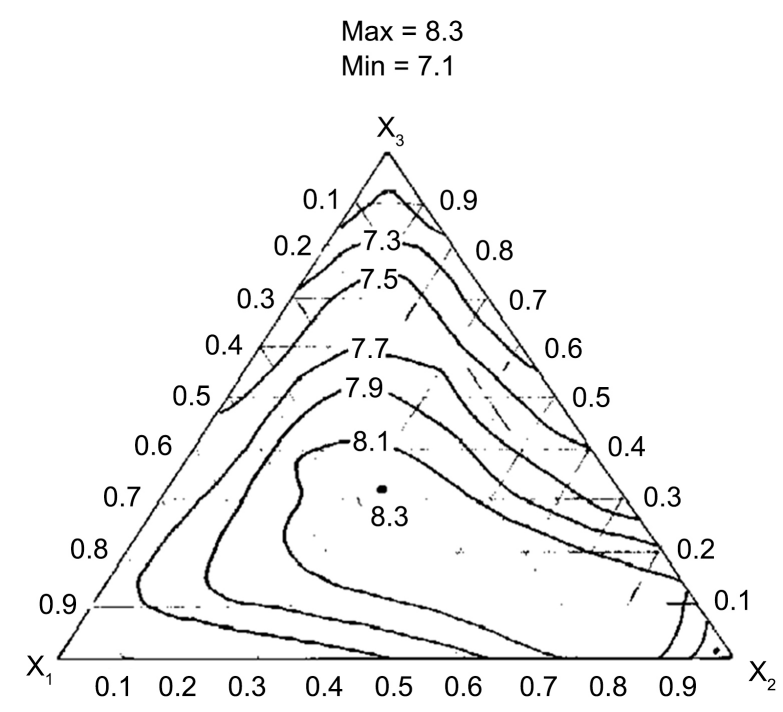

Figure 8. Elongation of the reinforced yarn, \%.

\subsection{Comparative Analysis of Yarns of Various Reinforcement Methods}

In the literature review of the chapter 1.2, various reinforcement methods were considered, such as annular, rotary, aerodynamic.

At present, valuable fibers are used in the production of pile fabrics from reinforced yarn. However, these fabrics can be made from yarns made from fiber waste on a rotary machine.

For this, in turn, leads to savings in valuable raw materials and a reduction in technological processes of spinning [5].

For comparative analysis, sortings were drawn up, which are indicated in chapter/3.2/. Semi-finished products, strap and roving were obtained from these grades. The studied physical and mechanical properties of semi-finished products are suggested in the following Table 7.

It can be seen from the table that the linear density, and the uneven linear density, meet the requirements of GOST.

To achieve the goal, a reinforced yarn was produced from fibrous waste, consisting of $50 \%$ core yarn made from valuable fiber and $50 \%$ of an upholstery layer consisting of fibrous waste from spinning-twisting and rotary machines. After that, the physical and mechanical properties of the resulting yarn were fully studied and its comparative characteristics are given in Table 8.

The table shows that when yarn is produced from fibrous waste, its physical and mechanical properties slightly differ from the properties of yarn obtained from valuable fiber. The main reason for this is that the upholstery yarn is derived from waste fiber and consists of short fibers, despite accounting for 50\% of the total weight of the twisted yarn.

Table 9 shows that the yarn produced by the rotary method, in its properties, exceeds the indicators of the yarn produced by the ring method. In addition, a slight twist of the yarn makes it possible to obtain a more pile fabric. 
Table 7. Physical and mechanical properties of polyfineries.

\begin{tabular}{ccccc}
\hline No. & $\begin{array}{c}\text { Name of semi-finished } \\
\text { products }\end{array}$ & $\begin{array}{c}\text { Linear density, } \\
\text { T, tex }\end{array}$ & $\begin{array}{c}\text { Unevenness, } \\
\text { in } \%\end{array}$ & $\begin{array}{c}\text { State Standard } \\
\text { (SS) }\end{array}$ \\
\hline 1 & Waste Cotton Canvas & 420 & 1.6 & 1.5 \\
2 & VISCOSE WASTE CANVAS & 400 & 2.3 & 1.9 \\
3 & Polyester Waste Canvas & 400 & 1.9 & 1.7 \\
4 & Cotton waste combed tape & 3.81 & 4.6 & 5.6 \\
5 & Cardboard viscose tape from & 3.67 & 3.1 & 5.6 \\
6 & Polyester comb tape from. & 3.67 & 3.7 & 5.6 \\
7 & Belt from draw frames & 3.62 & 2.1 & $2.1+2.5$ \\
8 & roving & 625 & 1.7 & $2.1+2.5$ \\
\hline
\end{tabular}

Table 8. Comparative characteristics of yarn properties.

\begin{tabular}{lccc}
\hline \multicolumn{1}{c}{ Yarn indicators } & Core thread & $\begin{array}{c}\text { In the factory, } \\
\text { conv. made of } \\
\text { valuable fibers }\end{array}$ & $\begin{array}{c}\text { In the factory, } \\
\text { conv. from } \\
\text { fiber waste }\end{array}$ \\
\hline Linear density of the yarn, tex & 24.8 & $49.9(25 \times 2)$ & $49.7(25 \times 2)$ \\
Breaking load, R.sn & 295.12 & 663.17 & 631.19 \\
Relative breaking load. Roth sn/tex & 11.9 & 13.3 & 12.7 \\
Twist, K, cr/m & 796 & 573 & 34.3 \\
Twist coefficient of variation, in \% & 38.7 & 41.4 & 3.67 \\
- by linear density & 4.0 & 2.6 & 10.6 \\
\hline
\end{tabular}

Table 9. Comparative table of physical and mechanical properties of reinforced yarn.

\begin{tabular}{cccc}
\hline Yarn parameters & & \multicolumn{2}{c}{ From Waste fiber } \\
\cline { 2 - 3 } Linear density of the yarn, tex & Core filament & Rotary way \\
Breaking load, R.sn & 24.8 & $49.7(25.2)$ & 50.9 \\
Relative breaking load, & 295.12 & 631.19 & 692.24 \\
Rotary, CN/tex. Twist, cr/m & 11.9 & 12.7 & 442 \\
Twist factor & 796 & 488 & 36.9 \\
Rough coefficient, $\%$ & 38.7 & 34.3 & 2.6 \\
Linear density & & & 12.3 \\
breaking load & 4.0 & 3.67 & 10.8 \\
\hline
\end{tabular}


The experiments have shown that when producing reinforced yarn from fibrous waste, the rotary spinning method makes it possible to obtain pile fabric of the flannel type. At the same time, the use of spinning waste allows you to save valuable raw materials, shorten the technological process of yarn production, and also increase the productivity of labor and equipment.

From the above analysis of the yield of the reinforced yarn, it was found that the quality of the yarn is largely influenced by the core thread. Further research is aimed at studying the methods of feeding the core thread.

\section{Conclusions}

1) Studied the properties of fiber waste from spinning production. The main physical and mechanical indicators of fibrous waste, as a raw material for yarn, as having reduced staple length characteristics, but possessing the necessary physical and mechanical properties, including hygroscopicity, appearance, which is very valuable in the production of pile fabrics (flannel, boomazy), have been determined.

2) The interrelationship of the composition of the sorting components with the properties of the yarn has been investigated in a simplex planning of optimizing the composition of the mixture.

3) On the basis of experiments, the optimal ratios of components have been established that ensure the required quality of a single yarn.

4) Reinforced yarn has been obtained experimentally in a circular and rotary way. The qualitative indicators of the yarn of the rotary reinforcement method were compared and selected.

\section{Conflicts of Interest}

The author declares no conflicts of interest regarding the publication of this paper.

\section{References}

[1] Polyakova, D.A., Ermilov, G.A., Drozdov, N.A., et al. (1987) Rotary Method of Spinning and Reinforcement M: Legprom-Bytizdat. (The Course of Accelerating Scientific and Technological Progress).

[2] Application 62-238830 Japan, MKI D 01 H 7/02 (2010) Device for Making Reinforced Yarn/Shinoko Matsu no. Appl. 4.04.86, N 60-126598.

[3] Grekova, S.V., Polyakova, D.A., Tsnikhbi, N.A.D., Moscow, L.V. and Yaroslavl, K.V. (1990) Rotary Reinforcement Technology Is One of the Ways to Save Natural Fiber. Textile Industry, Moscow, 40-42.

[4] Pat. 4899529 USA, MKI D 01 H 13/16, D 01 G 15/00 (2013) Method for Making Reinforced Yarn/Fumio Tanae. Appl. 12.12.88 283308.

[5] Bezin, P.V. (1993) Optimization of the Production Technology of Reinforced Yarn on a Ring Spinning Machine. Dissertation for the Degree of Candidate of Technical Sciences. St. Petersburg.

[6] Aktayeva, U., Abzalova, D., Bektureyeva, G., Ibragimova, Z. and Baizhanov, A. 
(2018) Methodological Aspects of Research of Materials' Crack Growth Resistance Assessment at Cyclic Loading. Industrial Technology and Engineering, 26, 11-21.

[7] Dzhanpaizova, V.M., Ashirbekova, G.Sh., Aripbaeva, A.E. and Asanov, Zh.E. (2019) Technology for Improving the Quality of Rotor Yarn by Regenerating Waste from Spinning Production Technology of the Textile Industry.

[8] Khaidarov, Kh.H and Ismailov, N.T. (2020) The Effect of Torsion on the Mechanical Properties of Reinforced Yarn. International Journal of Engineering and Technical Research, 9. https://doi.org/10.17577/IJERTV9IS020259

https://www.researchgate.net/publication/341872687_The_Effect_of_Torsion_on_t he_Mechanical_Properties_of_Reinforced_Yarn

[9] Ismoilov, N.T. and Khaidarov, Kh.Kh. (2020) Selection of Parameters for Twisting of Reinforced Yarn. U55 Universum: Engineering Sciences: A Scientific Journal, 72, 12-16. http://7universum.com/ru/tech/archive/category/372

[10] Khaidarov, Kh.Kh. and Ismailov, N.T. (2020) Feasibility of Using Yarn Reinforcement for Fiber Waste Disposal. Journal “Internauka”, 134, 58.

https://www.internauka.org/journal/science/internauka/134 